\title{
Relationship between recurrent ischemic events in cerebrovascular disease and cytochrome P450 2C19 gene polymorphism on the basis of thrombelastography
}

\author{
Jiaming Liu", Yulong Zhao", He Chen, Fangyu Yang, Ligang Chen, Guangzhi Hao, Xu Gao \\ Department of Neurosurgery, The Northern Theater General Hospital, Shenyang, China \\ Contributions: (I) Conception and design: J Liu, Y Zhao, X Gao; (II) Administrative support: Y Zhao; (III) Provision of study materials or patients: \\ H Chen, F Yang, L Chen, G Hao, X Gao; (IV) Collection and assembly of data: All authors; (V) Data analysis and interpretation: J Liu, H Chen, F \\ Yang, L Chen, G Hao; (VI) Manuscript writing: All authors; (VII) Final approval of manuscript: All authors. \\ \#These authors contributed equally to this work. \\ Correspondence to: Xu Gao. No.83 Wenhua Road, Shenhe District, The Northern Theater General Hospital, Shenyang, China. \\ Email: gaoelmer@hotmail.com.
}

\begin{abstract}
Background Recurrent ischemic events in cerebrovascular disease present a difficult problem in clinical practice. The predictive value of cytochrome P450 2C19 (CYP2C19) gene polymorphism and high platelet reactivity for recurrent ischemic events in cerebrovascular disease is not clear.

Methods: A total of 295 patients with acute ischemic cerebrovascular disease admitted to the cerebrovascular disease center of Northern Theater General Hospital between January 1, 2020 and February 2, 2021 were enrolled in this study. Thrombelastography (TEG) was used to detect platelet reactivity and CYP2C19 gene polymorphism.

Results: Among the 118 noncarriers, 97 had normal platelet reactivity and 21 had high platelet reactivity. Of the 177 carriers, 120 showed normal platelet reactivity and 57 showed high platelet reactivity. The area under the curve (AUC) of CYP2C19 gene polymorphism in predicting recurrent ischemic events was 0.66 . The regression coefficients of hypertension, stroke history, carriers, and high platelet reactivity with recurrent ischemic events were $0.341,0.402,0.358$, and 0.281 , respectively, with significant positive correlation $(\mathrm{P}<0.05)$.

Conclusions: Hypertension, stroke history, carriers, and high platelet reactivity are all independent risk factors for recurrent ischemic events. CYP2C19 gene polymorphism and high platelet reactivity can be used as effective predictors of recurrent ischemic events in clinical cerebrovascular disease.
\end{abstract}

Keywords: Cerebrovascular disease; recurrent ischemic event; thrombelastography; cytochrome P450 (CYP) 2 C19 gene polymorphism; high platelet reactivity

Submitted Nov 25, 2021. Accepted for publication Jan 19, 2022.

doi: 10.21037/apm-21-3775

View this article at: https://dx.doi.org/10.21037/apm-21-3775

\section{Introduction}

Ischemic stroke refers to cerebral blood supply disorders, ischemia, and hypoxia leading to ischemic necrosis or softening of local brain tissue $(1,2)$. Statistics show that China's annual number of new strokes is $1.5-2$ million, the annual incidence is $116-219 / 100,000$, and annual mortality is $58-42 / 100,000$, making stroke China's leading cause of death. Ischemic stroke usually occurs in people over 50-60 years of age, often with atherosclerosis, hypertension, rheumatic heart disease, coronary heart disease, or diabetes, and smoking, drinking, and other unhealthy lifestyle habits (3-5). Few ischemic stroke patients are completely cured, and there is a high recurrence rate. The annual recurrence rate of ischemic stroke in China is as high as $17.7 \%$, while the recurrence rate of stroke in 10 years can reach $39.2 \%$ (6). Therefore, reducing recurrent ischemic events of acute ischemic cerebrovascular disease has significant economic and social benefits. Studies have shown that eroded or destroyed 
atherosclerotic plaques, the basis of thrombosis, are exposed to circulating platelets $(7,8)$. Through the endogenous coagulation pathway, platelets are rapidly activated, resulting in the secretion of its granular content including adenosine diphosphate (ADP), which stimulates platelet aggregation, eventually leading to thrombosis (9). Therefore, the prevention of platelet aggregation is important for preventing thrombosis in acute ischemic cerebrovascular disease.

When transformed into active thiol metabolite (SR 26334), clopidogrel inhibits ADP-induced platelet activation through the isoenzyme of hepatocyte cytochrome P450 (CYP). The activity of $\mathrm{P} 450$ isoenzyme is mainly affected by the cytochrome P450 2C19 (CYP2C19) gene. Gu et al. [2014] extracted peripheral blood from 299 ischemic stroke patients and 295 healthy controls. Genotyping using polymerase chain reaction-restriction fragment length polymorphism showed that the CYP2C19 681AA genotype may be an independent risk factor for ischemic stroke and recurrent stroke (10). Mega et al. showed that compared with noncarriers, the active metabolite of clopidogrel decreased $32.4 \%$ in healthy subjects carrying CYP2C19 functional deficiency genes. After taking clopidogrel, the platelet inhibition rate of carriers decreased by $9 \%$ compared with noncarriers (11). Pan et al. [2017] retrospectively explored the relationship between genetic polymorphism and the efficacy of clopidogrel in patients with ischemic stroke or transient ischemic attack, and proposed that carriers of CYP2C19 allele loss (*2, *3 and *8) had a higher risk of stroke and complex vascular events than non-carriers (12). Yang et al. [2020] tested the effects of ticaggrel and clopidogrel on platelet reactivity in patients with mild stroke or transient ischemic attack (TIA), and divided them into carriers and non-carriers according to the status of CYP2C19 allele loss. The results showed that ticagor/aspirin clopidogrel had a low platelet reactivity ratio in carriers, but not in noncarriers (13). Wu et al. [2018] enrolled 1,476 patients with mild stroke or transient ischemic attack who were treated with clopidogrel and aspirin, and investigated whether decreased renal function would change the relationship between CYP2C19 gene variation and clinical outcomes. Classification based on the quartile of renal function estimated by glomerular filtration rate (eGFR) found that the CYP2C19 allele carriers in the lowest quartile of renal function had a higher incidence of new stroke than non-carriers (14). Clinical detection methods for platelet function mainly include light transmittance aggregometry (LTA), platelet function analysis, VerifyNOW assay, and thrombelastography (TEG). TEG is an analyzer which can dynamically monitor the entire coagulation process (15).
Unlike a blood coagulation analyzer, TEG can fully reflect interaction among platelets, coagulation factors, fibrinogen, the fibrinolytic system, and other cellular components from coagulation to fibrinolysis by detecting a small amount of whole blood. TEG is easy to operate and produces accurate data for the comprehensive monitoring of the entire process of coagulation and fibrinolysis and platelet function.

In patients with acute ischemic cerebrovascular disease, the relationship between CYP2C19 gene polymorphism, clopidogrel high platelet reactivity, and recurrent ischemic events has not been well studied. Hence, this study used TEG to detect clopidogrel high platelet reactivity and CYP2C19 genotype to detect CYP2C19 gene polymorphism. Further, we evaluated the relationship between CYP2C19 gene polymorphism, clopidogrel high platelet reactivity, and recurrent ischemic events. The purpose of this study was to evaluate the effects of CYP2C19 gene polymorphism and clopidogrel high platelet reactivity on recurrent ischemic events in patients with acute ischemic cerebrovascular disease. We present the following article in accordance with the MDAR reporting checklist (available at https://apm. amegroups.com/article/view/10.21037/apm-21-3775/rc).

\section{Methods}

\section{Research objects}

A total of 295 patients with acute ischemic cerebrovascular disease hospitalized in the cerebrovascular disease center of Northern Theater General Hospital between January 1, 2020 and February 2, 2021 were selected as subjects. Among them, there were 163 males and 132 females, aged 45-71 years old. Basic clinical data were collected, including age, gender, body mass index (BMI), hypertension, diabetes, smoking, and stroke history. The study was conducted in accordance with the Declaration of Helsinki (as revised in 2013). The study was approved by the Research Ethics Committee of The Northern Theater General Hospital [No.: Y (2021)080]. Patients and their families understood the research and signed an informed consent form.

Inclusion criteria were patients who (I) were older than 18 years, (II) took aspirin and clopidogrel, (III) had complete clinical data, and (IV) gave informed consent.

Exclusion criteria were patients with (I) epicardial embolism, (II) a history of clopidogrel allergy, (III) aspirin allergy history; and patients who (IV) took other anticoagulant drugs in March, (V) had hematological diseases, and (VI) received intravenous thrombolysis. 


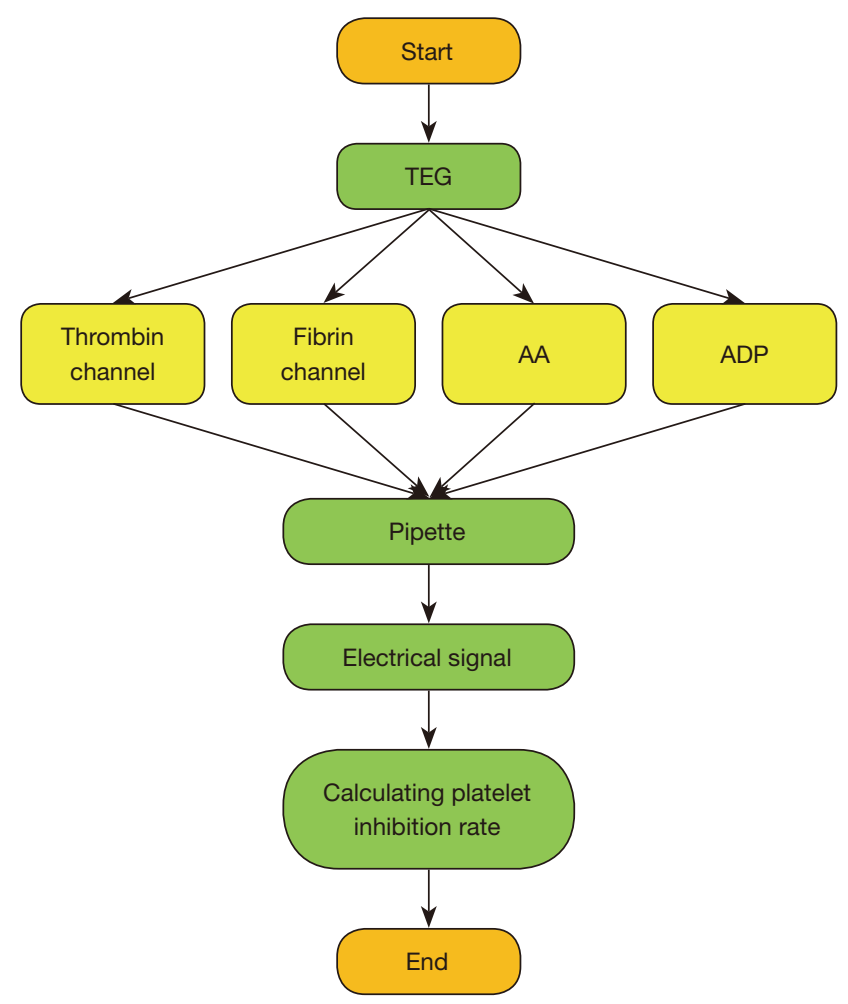

Figure 1 TEG detection process. TEG, thrombelastography; AA, arachidonic acid; ADP, adenosine diphosphate.

\section{TEG detection}

TEG was performed within 2 hours after venous blood sampling (16) (Figure 1). Platelet reactivity was measured using an improved TEG platelet mapping system (Haemoscope Corp., Braintree, MA, USA) according to the manufacturer's instructions. The improved TEG used 4 channels to detect platelet reactivity through arachidonic acid (AA) and ADP pathways, including: (I) thrombin channel, containing kaolin to induce maximum thrombin activation; (II) fibrin channel, containing activator $\mathrm{F}$ (a mixture of reptilase and coagulation factor XIIIa); (III) AA channel containing activator F and AA; and (IV) ADP channel containing activator $\mathrm{F}$ and ADP. Whole blood was drawn to each channel by a fluid shifter consisting of an oscillating cup and a suspension needle. Viscoelasticity change occurring during blood clot formation was transmitted to the probe and the resulting torque generated an electrical signal recorded by TEG. The AA- or ADPinduced platelet inhibition rate was calculated by computer software according to the following equation.

$$
\text { Suppression ratio }=\frac{\mathrm{MA}_{1 \text { or } 2}-\mathrm{MA}_{3}}{\mathrm{MA}_{4}-\mathrm{MA}_{3}} \times 100 \%
$$

$\mathrm{MA}_{1}$ represents AA-induced clot strength, $\mathrm{MA}_{2}$ represents $\mathrm{ADP}$-induced clot strength, $\mathrm{MA}_{3}$ represents fibrin-induced clot strength, and $\mathrm{MA}_{4}$ represents thrombininduced clot strength

Based on the results of cardiovascular disease (17), the boundary value of clopidogrel high platelet reactivity was defined as ADP-induced $<30 \%$ platelet inhibition rate detected by TEG, and the boundary value of aspirin high platelet reactivity was defined as AA-induced $<50 \%$ platelet inhibition rate detected by TEG. A platelet inhibition rate higher than the above threshold was defined as normal platelet reactivity.

\section{Genotype detection of CYP2C19}

The detection process involved extracting whole blood samples using a QIAGEN blood kit (QIAGEN, Chatsworth, CA, USA) according to the manufacturer's instructions. DNA microarray (gene chip) was used to evaluate CYP2C19 genotype. $C Y P 2 C 19^{*} 2$ and $C Y P 2 C 19^{*} 3$ alleles were determined using the $\mathrm{BaiO} \mathrm{BE}-2.0$ biochip diagnostic analyzer (BaiO Technology Co., Ltd., Shanghai, China). DNA extraction procedures, polymerase chain reaction amplification, hybridization, gene chip detection, and analysis were performed strictly in accordance with the genotype detection gene chip kit manual (BaiO Technology Co., Ltd.).

CYP2C19 genotype grouping (18) was carried out according to the pharmacokinetic characteristics of clopidogrel among different genotypes. Wild-type gene ${ }^{*} 1 /{ }^{*} 1(636 \mathrm{GG} / 681 \mathrm{GG})$ was classified as noncarrier. Mutation hybrid *1/*2(636GG/681GA), *1/*3 (636GA/681GG), mutation homozygous *2/*2(636GG/681AA), *2/*3(636GA/681GA), and *3/*3 (636AA/681GG) were classified as having at least 1 functional deletion allele carrier and referred to as carrier.

\section{Endpoint events}

Outpatient and telephone follow-up was conducted. The patients were followed up for 3 months and 6 months after discharge for recurrent ischemic events, including recurrent ischemic stroke, transient ischemic attack (TIA), cerebrovascular surgery (angioplasty/stenting, carotid endarterectomy), myocardial infarction, stable angina, 


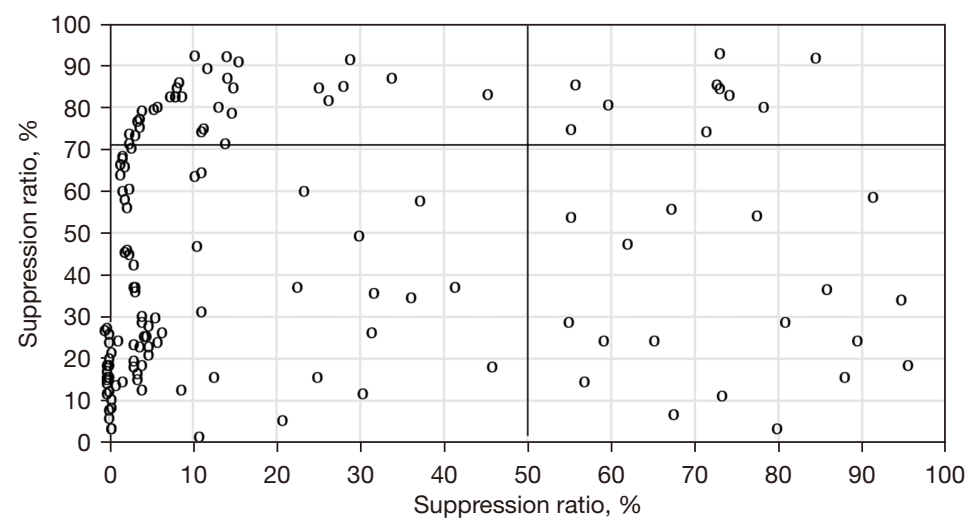

Figure 2 High platelet reactivity distribution in patients. The upper left quadrant is clopidogrel high platelet reactivity. The lower left quadrant is normal platelet response. The upper right quadrant is the high platelet response of clopidogrel and aspirin. The lower right quadrant is aspirin high platelet reactivity.

cardiovascular surgery (coronary artery bypass grafting, angioplasty/stenting), and lower extremity arterial disease or vascular death.

\section{Statistical methods}

The data in this study were analyzed by SPSS 19.0 statistical software. The measurement data are expressed as mean \pm standard deviation $\left(\bar{x}_{ \pm \mathrm{s}}\right)$, and count data are expressed as percentage (\%). Single factor analysis of variance was used for pairwise comparison. The difference was considered statistically significant with $\mathrm{P}<0.05$. The receiver operating characteristic (ROC) curve was used to evaluate the accuracy of high platelet reactivity, CYP2C19 gene polymorphism, and CYP2C19 gene polymorphism combined with high platelet reactivity in predicting recurrent ischemic events in patients. Kaplan-Meier method was used to synthesize cumulative survival curves of patients based on clopidogrel platelet reactivity, CYP2C19 genotype, and CYP2C19 genotype combined with clopidogrel platelet reactivity. The logrank test was used to evaluate the statistical difference in survival curves, and least significant difference (LSD) correction was used for comparison between groups. Multivariate Cox regression analysis was used to determine the related variables affecting clinical endpoint events.

\section{Results}

\section{Distribution of high platelet reactivity in patients}

The distribution of high platelet reactivity in patients is shown in Figure 2. In 295 patients, 217 cases (73.88\%) had normal platelet reaction, 10 cases (3.4\%) had clopidogrel and aspirin high platelet reaction, 49 cases $(5.44 \%)$ had clopidogrel high platelet reaction, and 19 cases (6.44\%) had aspirin high platelet reaction.

\section{Distribution of CYP2C19 gene polymorphism in patients}

The distribution of CYP2C19 gene polymorphism in patients is shown in Figure 3. Figure $3 A$ shows that in 295 patients, 118 cases $(39.97 \%)$ carried wild-type genes, 131 cases $(44.56 \%)$ carried mutant heterozygous genes, and 46 cases (15.65\%) carried mutant homozygous genes. Figure $3 B$ shows that among 131 patients carrying mutant heterozygous genes, 115 patients carried ${ }^{*} 1 /{ }^{*} 2$ and 16 patients carried ${ }^{*} 1 /{ }^{*} 3$. Figure $3 C$ shows that among the 46 patients carrying mutant homozygous genes, 27 patients carried ${ }^{*} 2 /{ }^{*} 2,14$ patients carried ${ }^{*} 2 / * 3$, and 5 patients carried $* 3 / * 3$.

\section{Relationship between CYP2C19 gene polymorphism and platelet reactivity in patients}

Figure 4 shows the comparison of platelet reactivity in noncarriers and carriers. Among the 118 noncarriers, 97 cases $(82.2 \%)$ showed normal platelet reactivity and 21 cases $(17.8 \%)$ showed high platelet reactivity. Of the 177 carriers, 120 cases $(67.8 \%)$ showed normal platelet reactivity and 57 cases $(32.2 \%)$ showed high platelet reactivity.

Further analysis of different types of gene carriers (Figure 5) found that in 131 patients with mutant heterozygous genes, 94 cases showed normal platelet reactivity and 37 cases showed high platelet reactivity. 

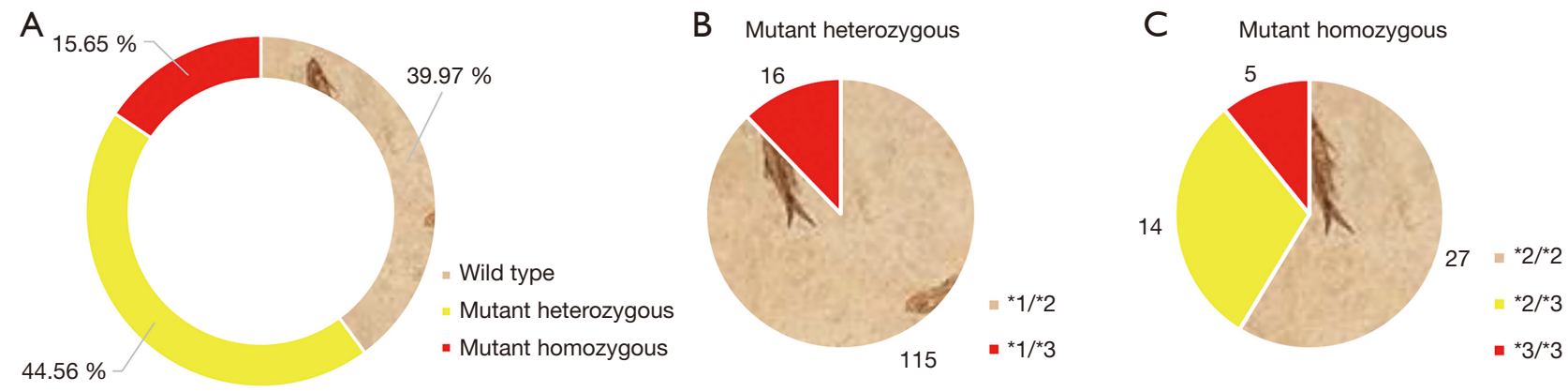

Figure 3 Distribution of CYP2C19 gene polymorphism in patients. (A) The proportion of wild type, mutant heterozygous, and mutant homozygous genes. (B) The proportion of ${ }^{*} 1 /{ }^{*} 2$ and ${ }^{*} 1 / * 3$ in mutant heterozygous genes. (C) The proportion of *2/*2, $2 /{ }^{*} 3$, and ${ }^{*} 3 /{ }^{*} 3$ in homozygous mutant genes.

A

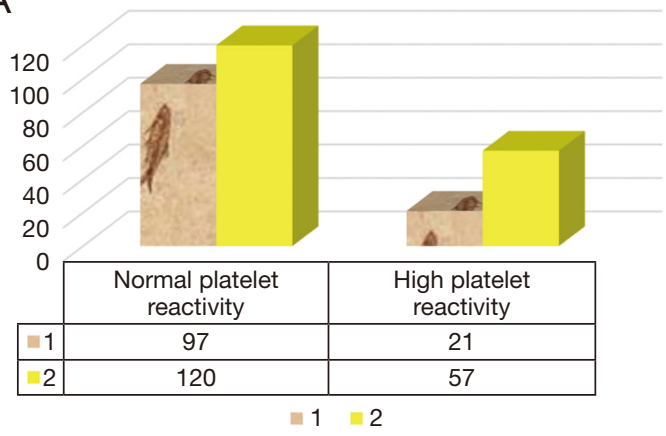

B

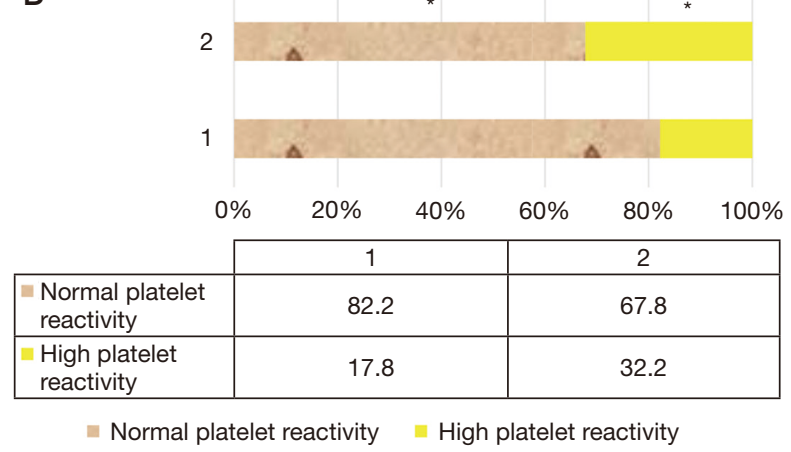

Figure 4 Comparison of platelet reactivity between noncarriers and carriers ( 1 is noncarriers, 2 is carriers). (A) The number of cases, and (B) the proportion. *, represents statistical differences versus $1(\mathrm{P}<0.05)$.

Among the 46 patients carrying mutant homozygous genes, 32 showed normal platelet reactivity and 14 showed high platelet reactivity. To further analyze the relationship between CYP2C19 gene polymorphism and platelet reactivity, one-way ANOVA (Figure $4 B$ ) showed that the proportion of carriers with high platelet reactivity was significantly higher than that of non-carriers $(\mathrm{P}<0.05)$, and that the proportion of normal platelet reaction in carriers was significantly lower than that in non-carriers $(\mathrm{P}<0.05)$. Spearmam correlation analysis showed that there was an extremely significant positive correlation between high platelet reactivity and CYP2C19 gene polymorphism $(\mathrm{R}=0.751, \mathrm{P}<0.001)$.

\section{ROC curve analysis of high platelet reactivity and CYP2C19 gene polymorphism in predicting recurrent ischemic events in patients}

Figure 6 shows the ROC curve of high platelet reactivity and CYP2C19 gene polymorphism for predicting recurrent ischemic events in patients. The AUC of recurrent ischemic events predicted by high platelet reactivity was 0.57 , and the AUC of recurrent ischemic events predicted by CYP2C19 gene polymorphism was 0.66 .

Figure 7 shows the ROC curve of high platelet reactivity and CYP2C19 gene polymorphism in predicting recurrent ischemic events in patients. The AUC of high platelet reactivity and CYP2C19 gene polymorphism in predicting recurrent ischemic events in patients was 0.71 .

\section{Survival analysis of high platelet reactivity, CYP2C19 gene polymorphism, and recurrent ischemic events}

Survival analysis of high platelet reactivity and recurrent ischemic events is shown in Figure 8. The survival rate of patients with high platelet reactivity was significantly lower than that of patients with normal platelet reactivity, and 

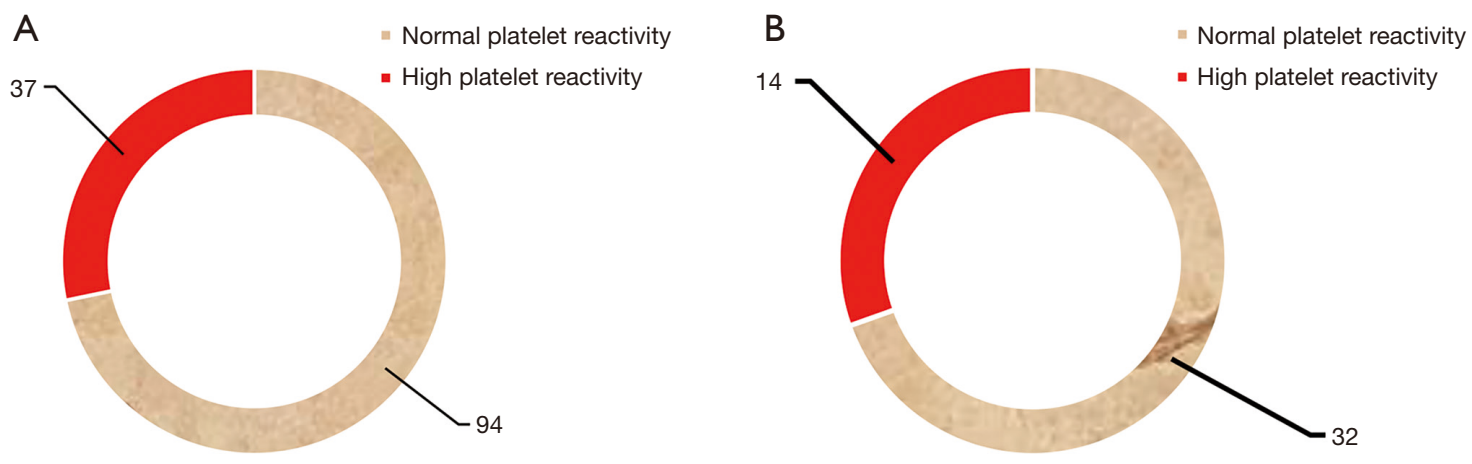

Figure 5 Platelet reactivity of different types of gene carriers. (A) Patients carrying mutant hybrid genes, and (B) patients carrying mutant homozygous genes.
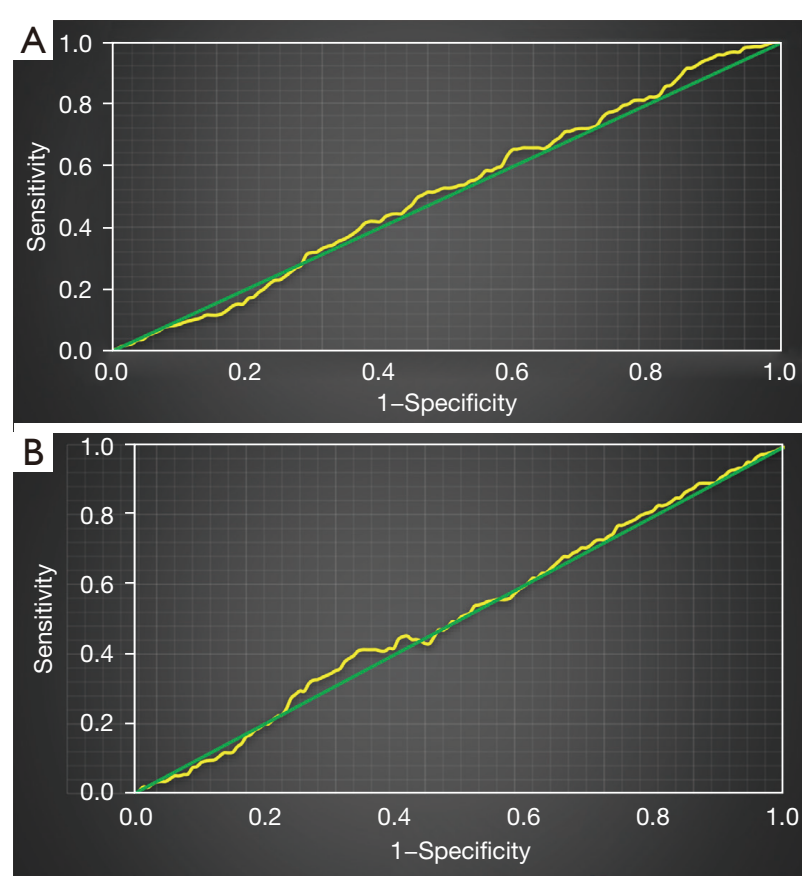

Figure 6 ROC curve of high platelet reactivity and CYP2C19 gene polymorphism in predicting recurrent ischemic events in patients. (A) CYP2C19 gene polymorphism, and (B) high platelet reactivity. ROC, receiver operating characteristic

there was a high risk of recurrent ischemic events.

Figure 9 shows survival analysis of CYP2C19 gene polymorphism and recurrent ischemic events. The survival rate of carriers was significantly lower than that of noncarriers, and there was a high risk of recurrent ischemic events.

Figure 10 shows survival analysis results of combined application of high platelet reactivity, CYP2C19 gene

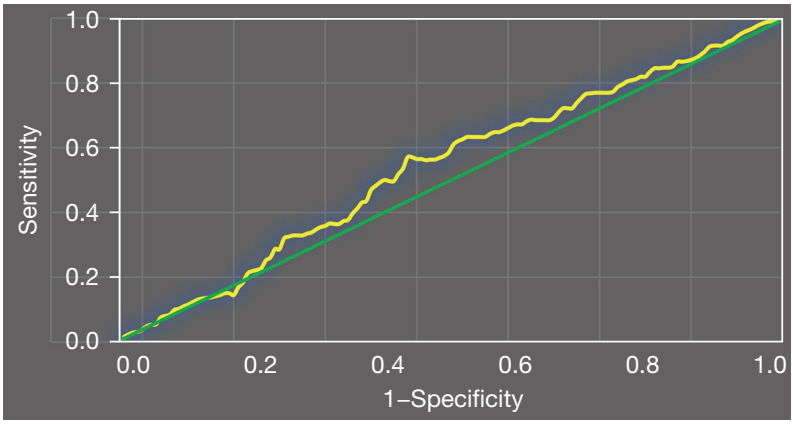

Figure 7 ROC curve of high platelet reactivity and CYP2C19 gene polymorphism in predicting recurrent ischemic events in patients.

polymorphism, and recurrent ischemic events. Survival rates of patients with carrier + high platelet reactivity were significantly lower than those of patients with carrier + normal platelet reactivity, noncarrier + normal platelet reactivity, and noncarrier + high platelet reactivity.

\section{Analysis of related factors of recurrent ischemic events in patients}

Single factor logistic regression analysis was performed with age, gender, BMI, hypertension, diabetes, smoking, stroke history, carriers, and high platelet reactivity as independent variables, and recurrent ischemic events as the dependent variable. As shown in Table 1, the $\mathrm{P}$ values of age, gender, BMI, smoking, and recurrent ischemic events were all greater than 0.05 , indicating that there was no significant correlation. The regression coefficients of hypertension, diabetes, stroke history, carriers, and high platelet reactivity with recurrent ischemic events were $0.441,0.386,0.457$, 


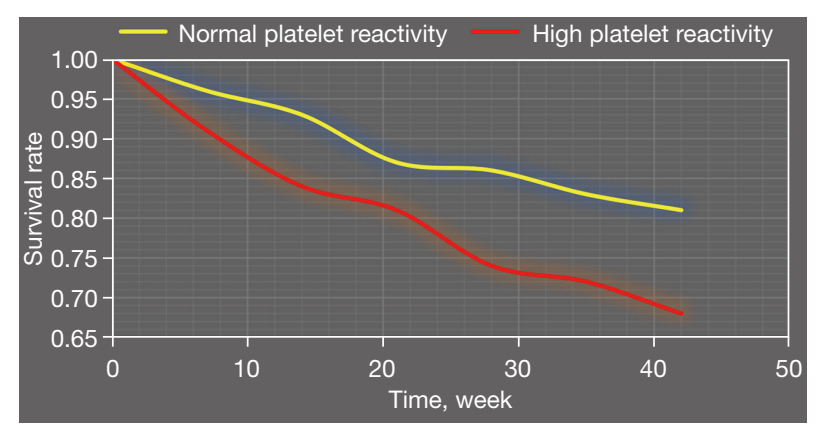

Figure 8 Survival analysis of high platelet reactivity and recurrent ischemic events.

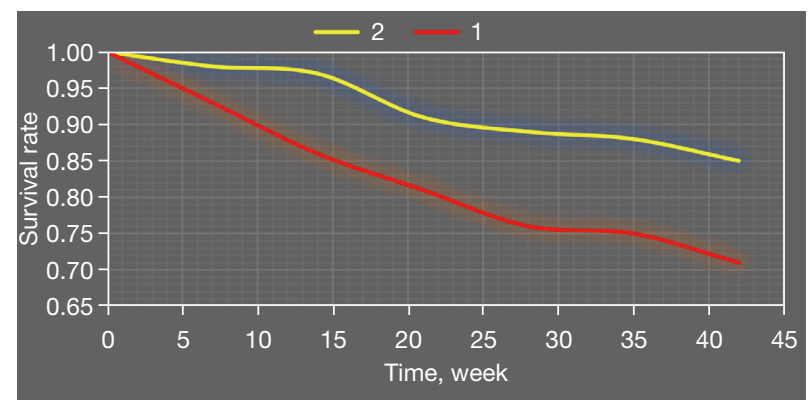

Figure 9 Survival analysis of CYP2C19 gene polymorphism and recurrent ischemic events ( 1 is carriers, 2 is noncarriers).

0.422 , and 0.407 , respectively, and there was a significant positive correlation $(\mathrm{P}<0.05)$.

Multivariate logistic regression analysis was performed with hypertension, diabetes, stroke history, carriers, and high platelet reactivity as independent variables and recurrent ischemic events as the dependent variable. As shown in Table 2, the regression coefficients of hypertension, stroke history, carriers, high platelet reactivity with recurrent ischemic events were 0.341, 0.402, 0.358, and 0.281 , respectively, with significant positive correlation $(\mathrm{P}<0.05)$.

\section{Discussion}

The recurrence of ischemic events is a major concern in clinical practice, and an effective prevention and treatment method is necessary $(19,20)$. Our study included 295 patients with acute ischemic cerebrovascular disease who were hospitalized in the cerebrovascular disease center of Northern Theater General Hospital between January 1, 2020 and February 2, 2021. Basic clinical data such as age,

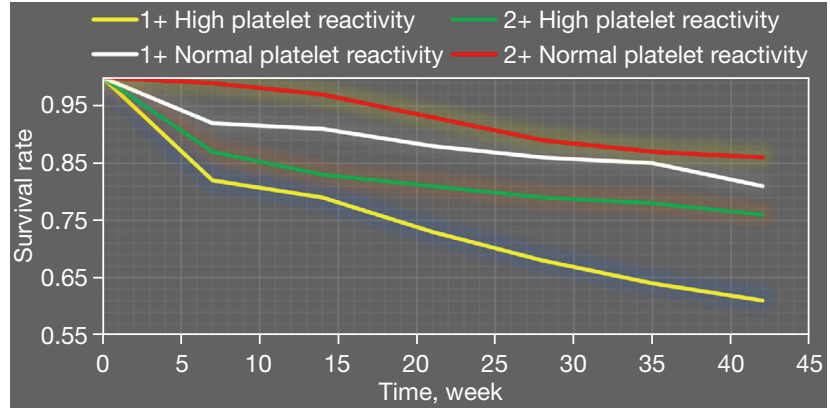

Figure 10 Combined application of high platelet reactivity and CYP2C19 gene polymorphism and survival analysis of recurrent ischemic events ( 1 is carriers, 2 is noncarriers).

gender, BMI, hypertension, diabetes, smoking, and stroke history of the patients were collected, and patient platelet reactivity and CYP2C19 gene polymorphism were detected by TEG (21). The results showed that in 295 patients, 217 cases $(73.88 \%)$ had normal platelet reaction, 10 cases (3.4\%) had clopidogrel and aspirin high platelet reaction, 49 cases $(5.44 \%)$ had clopidogrel high platelet reaction, and 19 cases $(6.44 \%)$ had aspirin high platelet reaction. Our results were lower than those of Kagami et al. (22), due to the use of different criteria and platelet reaction test methods. CYP2C19 gene polymorphism in 118 noncarriers was analyzed, and 97 cases of normal platelet reactivity and 21 cases of high platelet reactivity were found. Among 177 carriers, 120 showed normal platelet reactivity and 57 showed high platelet reactivity, indicating that the CYP2C19 gene had a high mutation rate in cerebrovascular disease (23). According to one-way ANOVA for the proportion of high platelet reactivity, the proportion of carriers was significantly higher than that of non-carriers, while the proportion of normal platelet reactivity was significantly lower than that of non-carriers $(\mathrm{P}<0.05)$, indicating that high platelet reactivity may be associated with CYP2C19 gene polymorphism. Spearmam correlation analysis further showed that high platelet reactivity was significantly positively correlated with CYP2C19 gene polymorphism $(\mathrm{R}=0.751, \mathrm{P}<0.001)$. Further analysis of different types of gene carriers showed that there were 94 cases of normal platelet reactivity and 37 cases of high platelet reactivity in 131 patients with mutant heterozygous genes. Among the 46 patients carrying mutant homozygous genes, 32 cases presented normal platelet reactivity and 14 presented high platelet reactivity. The results were similar to those of Jukić et al. (24), indicating that CYP2C19 
Table 1 Single factor logistic regression analysis of related factors of recurrent ischemic events in patients

\begin{tabular}{lccc}
\hline Index & Regression coefficient & $t$ & P \\
\hline Age & 0.205 & 2.414 & 0.051 \\
Gender & 0.188 & 1.964 & 0.078 \\
BMI & 0.197 & 2.681 & 0.074 \\
Hypertension & 0.441 & 4.271 & 0.035 \\
Diabetes & 0.386 & 3.953 & 0.046 \\
Smoking & 0.185 & 2.116 & 0.052 \\
Stroke history & 0.457 & 4.684 & 0.016 \\
Carriers & 0.422 & 4.229 & 0.023 \\
High platelet reactivity & 0.407 & 3.975 & 0.018 \\
\hline
\end{tabular}

BMI, body mass index.

Table 2 Multivariate logistic regression analysis of related factors of recurrent ischemic events in patients

\begin{tabular}{lccc}
\hline Index & Regression coefficient & $t$ & $P$ \\
\hline Hypertension & 0.341 & 3.861 & 0.039 \\
Diabetes & 0.318 & 3.175 & 0.050 \\
Stroke history & 0.402 & 4.025 & 0.031 \\
Carriers & 0.358 & 4.113 & 0.029 \\
High platelet reactivity & 0.281 & 3.673 & 0.021 \\
\hline
\end{tabular}

gene polymorphism may be related to platelet reactivity.

ROC curve analysis revealed that the AUC of recurrent ischemic events predicted by high platelet reactivity was 0.57 , and the AUC of recurrent ischemic events predicted by $C Y P 2 C 19$ gene polymorphism was 0.66 , indicating that CYP2C19 gene polymorphism was correlated with recurrent ischemic events (25). Survival analysis showed that the survival rate of patients with high platelet reactivity was significantly lower than that of patients with normal platelet reactivity. Survival analysis of $C Y P 2 C 19$ gene polymorphism and recurrent ischemic events suggested that the survival rate of carriers was significantly lower than that of noncarriers, which indicated that patients with high platelet reactivity and CYP2C19 gene carriers had higher risk of recurrent ischemic events. Age, gender, BMI, hypertension, diabetes, smoking, stroke history, carriers, and high platelet reactivity of patients were used as independent variables, and recurrent ischemic events was used as a dependent variable for regression analysis. Regression coefficients between hypertension, stroke history, carriers, and high platelet reactivity with recurrent ischemic events were
$0.341,0.402,0.358$, and 0.281 , respectively, with significant positive correlation $(\mathrm{P}<0.05)(26)$. The results showed that hypertension, stroke history, carriers, and high platelet reactivity were all independent risk factors for recurrent ischemic events, and thus CYP2C19 gene polymorphism and high platelet reactivity could be used to predict recurrent ischemic events in clinical cerebrovascular disease.

\section{Conclusions}

In this study, 295 patients with acute ischemic cerebrovascular disease who were hospitalized in the cerebrovascular disease center of Northern Theater General Hospital between January 1, 2020 and February 2, 2021 were selected. Clinical data, including age, gender, BMI, hypertension, diabetes, smoking, and stroke history, were collected. TEG was used to detect platelet reactivity and CYP2C19 gene polymorphism. The results showed that hypertension, stroke history, carriers, and high platelet reactivity were all independent risk factors for recurrent ischemic events. CYP2C19 gene polymorphism and high 
platelet reactivity could be used as effective predictors of recurrent ischemic events in clinical cerebrovascular disease. However, there was no intensive antiplatelet therapy for patients with high platelet response in this study, and a larger number of patients is needed for further discussion on the relationship between treatment regimens and prognosis. In conclusion, this study provides data support for the diagnosis and treatment of cerebrovascular diseases and the prediction and evaluation of recurrent ischemic events by discussing the relationship between hyper-platelet reactivity and recurrent ischemic events with CYP2C19 gene polymorphism, as well as the predictive value of efficacy and outcome in patients with hyper-platelet reactivity combined with CYP2C19 gene polymorphism.

\section{Acknowledgments}

Funding: None.

\section{Footnote}

Reporting Checklist: The authors have completed the MDAR reporting checklist. Available at https://apm.amegroups. com/article/view/10.21037/apm-21-3775/rc

Data Sharing Statement: https://apm.amegroups.com/ article/view/10.21037/apm-21-3775/dss

Conflicts of Interest: All authors have completed the ICMJE uniform disclosure form (available at https://apm. amegroups.com/article/view/10.21037/apm-21-3775/coif). The authors have no conflicts of interest to declare.

Ethical Statement: The authors are accountable for all aspects of the work in ensuring that questions related to the accuracy or integrity of any part of the work are appropriately investigated and resolved. The study was conducted in accordance with the Declaration of Helsinki (as revised in 2013). The study was approved by the Research Ethics Committee of The Northern Theater General Hospital [No.: Y (2021)080]. Patients and their families understood the research and signed an informed consent form.

Open Access Statement: This is an Open Access article distributed in accordance with the Creative Commons Attribution-NonCommercial-NoDerivs 4.0 International License (CC BY-NC-ND 4.0), which permits the noncommercial replication and distribution of the article with the strict proviso that no changes or edits are made and the original work is properly cited (including links to both the formal publication through the relevant DOI and the license). See: https://creativecommons.org/licenses/by-nc-nd/4.0/.

\section{References}

1. El Rouby N, Lima JJ, Johnson JA. Proton pump inhibitors: from CYP2C19 pharmacogenetics to precision medicine. Expert Opin Drug Metab Toxicol 2018;14:447-60.

2. Sienkiewicz-Oleszkiewicz B, Wiela-Hoje ska A. CYP2C19 polymorphism in relation to the pharmacotherapy optimization of commonly used drugs. Pharmazie 2018;73:619-24.

3. Bahar MA, Setiawan D, Hak E, et al. Pharmacogenetics of drug-drug interaction and drug-drug-gene interaction: a systematic review on CYP2C9, CYP2C19 and CYP2D6. Pharmacogenomics 2017;18:701-39.

4. Rath CL, Jørgensen NR, Wienecke T. Clopidogrel responder status is uninfluenced by CYP2C19*2 in Danish patients with stroke. PLoS One 2020;15:e0236260.

5. Solomon HV, Cates KW, Li KJ. Does obtaining CYP2D6 and CYP2C19 pharmacogenetic testing predict antidepressant response or adverse drug reactions? Psychiatry Res 2019;271:604-13.

6. Waring RH. Cytochrome P450: genotype to phenotype. Xenobiotica 2020;50:9-18.

7. Jukić MM, Haslemo T, Molden E, et al. Impact of CYP2C19 Genotype on Escitalopram Exposure and Therapeutic Failure: A Retrospective Study Based on 2,087 Patients. Am J Psychiatry 2018;175:463-70.

8. Price DJ, Levy MS. CYP2C19 pharmacogenetics in patients undergoing coronary stent placement: Is it time to test everyone? Catheter Cardiovasc Interv 2019;93:1253-4.

9. Charfi R, Mzoughi K, Boughalleb M, et al. Response to clopidogrel and of the cytochrome CYP2C19 gene polymorphism. Tunis Med 2018;96:209-18.

10. Gu S, Sun Y, Han R, et al. Association between genetic polymorphisms of cytochrome $\mathrm{P} 4502 \mathrm{C} 19$ and the risk of cerebral ischemic stroke in Chinese. BMC Med Genet 2014;15:83.

11. Mega JL, Close SL, Wiviott SD, et al. Genetic variants in ABCB1 and CYP2C19 and cardiovascular outcomes after treatment with clopidogrel and prasugrel in the TRITON-TIMI 38 trial: a pharmacogenetic analysis. Lancet 2010;376:1312-9.

12. Pan Y, Chen W, Xu Y, et al. Genetic Polymorphisms and Clopidogrel Efficacy for Acute Ischemic Stroke or 
Transient Ischemic Attack: A Systematic Review and MetaAnalysis. Circulation 2017;135:21-33.

13. Yang Y, Chen W, Pan Y, et al. Effect of ticagrelor versus clopidogrel on platelet reactivity measured by thrombelastography in patients with minor stroke or TIA. Aging (Albany NY) 2020;12:20085-94.

14. Wu Y, Zhou Y, Pan Y, et al. Impact of CYP2C19 polymorphism in prognosis of minor stroke or TIA patients with declined eGFR on dual antiplatelet therapy: CHANCE substudy. Pharmacogenomics J 2018;18:713-20.

15. Mohammad AM, Al-Allawi NAS. CYP2C19 Genotype is an Independent Predictor of Adverse Cardiovascular Outcome in Iraqi Patients on Clopidogrel After Percutaneous Coronary Intervention. J Cardiovasc Pharmacol 2018;71:347-51.

16. Meschia JF, Walton RL, Farrugia LP, et al. Efficacy of Clopidogrel for Prevention of Stroke Based on CYP2C19 Allele Status in the POINT Trial. Stroke 2020;51:2058-65.

17. Vu NP, Nguyen HTT, Tran NTB, et al. CYP2C19 genetic polymorphism in the Vietnamese population. Ann Hum Biol 2019;46:491-7.

18. Hassani Idrissi H, Hmimech $W$, Khorb NE, et al. A synergic effect between CYP2C19*2, CYP2C19*3 lossof-function and CYP2C19*17 gain-of-function alleles is associated with Clopidogrel resistance among Moroccan Acute Coronary Syndromes patients. BMC Res Notes 2018;11:46.

19. Pratt VM, Del Tredici AL, Hachad H, et al. Recommendations for Clinical CYP2C19 Genotyping Allele Selection: A Report of the Association for Molecular
Pathology. J Mol Diagn 2018;20:269-76.

20. Chen K, Zhang X, Ke X, et al. Individualized Medication of Voriconazole: A Practice Guideline of the Division of Therapeutic Drug Monitoring, Chinese Pharmacological Society. Ther Drug Monit 2018;40:663-74.

21. Bernal CJ, Aka I, Carroll RJ, et al. CYP2C19 Phenotype and Risk of Proton Pump Inhibitor-Associated Infections. Pediatrics 2019;144:e20190857.

22. Kagami T, Yamade M, Suzuki T, et al. Comparative Study of Effects of Vonoprazan and Esomeprazole on Antiplatelet Function of Clopidogrel or Prasugrel in Relation to CYP2C19 Genotype. Clin Pharmacol Ther 2018;103:906-13.

23. Saiz-Rodríguez M, Belmonte C, Román M, et al. Effect of Polymorphisms on the Pharmacokinetics, Pharmacodynamics and Safety of Sertraline in Healthy Volunteers. Basic Clin Pharmacol Toxicol 2018;122:501-11.

24. Jukić MM, Opel N, Ström J, et al. Elevated CYP2C19 expression is associated with depressive symptoms and hippocampal homeostasis impairment. Mol Psychiatry 2017;22:1155-63.

25. Tangamornsuksan W, Thiansupornpong P, Morasuk T, et al. A pharmacokinetic model of drug-drug interaction between clopidogrel and omeprazole at CYP2C19 in humans. Annu Int Conf IEEE Eng Med Biol Soc 2017;2017:2704-7.

26. Savadlou A, Arnatkeviciute A, Tiego J, et al. Impact of CYP2C19 genotype-predicted enzyme activity on hippocampal volume, anxiety, and depression. Psychiatry Res 2020;288:112984.
Cite this article as: Liu J, Zhao Y, Chen H, Yang F, Chen L, Hao G, Gao X. Relationship between recurrent ischemic events in cerebrovascular disease and cytochrome P450 2C19 gene polymorphism on the basis of thrombelastography. Ann Palliat Med 2022;11(1):240-249. doi: 10.21037/apm-21-3775 